\title{
Sonhos e lutas de organizações de mulheres negras na Grã-Bretanha
}

\author{
Outros tipos de sonhos: \\ organizações de mulheres \\ negras e políticas de \\ tra nsformação.
}

SUDBURY, J ulia.

Rio de J a neiro: Objetiva, 2005. 168 p.

O livro Outros tipos de sonhos: organizações de mulheres negras e políticas de transformação traça um histórico da trajetória de organizações de mulheresnegras na Grã-Bretanha e, pormeio da a nálise crítica que efetua, confere visibilida de a coerências e contradições nos discursos das integrantes desses movimentos. Sud bury embasa a sua pesquisa em uma perspectiva histórica, social e crítica, concebendo as orga niza ções de mulheres negras como históricas e em contínua transformação.

A obra resulta da pesquisa de doutorado da a utora, que investigou doze orga niza ções de mulheres negras, entrevistando 25 mulheres e mapeando as dific ulda dese a rea lid a de intema dessas organizações. Sudbury é inglesa, socióloga, com PhD em Sociologia, professora assistente no Mills College, em Oakland, e é a tivista negra atuando em organizações de mulheres negras, tendo dirigido a Agência Nacional de Desenvolvimento para o Setor Voluntário Negro, em Londres.

Tal pesquisa permite embasar discussões sobre gênero e negritude, tratados de modo imbricado. Traz contribuições tanto do ponto de vista teóric 0 , em virtude das a nálises e disc ussões conceituais que apresenta, como também metodológic 0 , a o se referirà s estra tégia sutiliza das para superar dificuldades com relação a procedimentos de coleta de dadose de análise e às reflexões acerca das implicações do embasamento teórico para a análise, situandose em uma perspectiva comprometida com o seu objeto de estud o e com as transforma ções socia is na luta das mulheres negras na Grã-Bretanha. Assim, realiza reflexões em busca de subsídios conceituais e metodológicos que possibilitem contribuir efetivamente para o alcance dos objetivos propostos, constituindo uma pesquisa engajada com a luta das mulheres negras orga niza das pelos seus direitose pela a firma ção na sociedade diante das discriminações e dos a ta ques sofridos. Nesse sentido, pode-se a firmar que a autora superou a dicotomia entre teoria e prática no contexto do ativismo das mulheres negras, mostrando preocupação em repensar conc eitos que limitam as ações da sorga nizações de mulheres. Superando tal dic otomia, a a utora procura articular teoria e prática estabelecendo uma relação em que se busca construir conceitos que embasam a ação, enquanto esta, por sua vez, conduz a uma re-construção conceitual. Além disso, o livro em questão ta mbém contribui para a atuação de outras organizações com objetivos semelhantesaos dos g rupos investiga dos pela autora, divulgando as experiências que ta mbém podem ser utilizadas por outras organizações autônomas, bem como concorre para dara conhecerta mbém para o público em geral, não só para teóricos, pesquisadores e a tivistas de movimentos socia is, diversos a spectos da realidade de mulheres negras e suas organizações.

A estrutura conceitual de análise da pesquisa constitui-se de quatro pontos principa is que instrumentalizaram o seu olhar diante das informações obtidas a tra vés das entrevistas: deixar de ver as mulheres como vítimas, mas sim como pessoas conscientes e atuantes; substituir a polític a de identidade porpolítica de posição, contemplando a especificidade de lugares socia is assumidos, com a própria a utora posicionando suas análises na perspectiva womanista; articular 'raça', classe e gênero; e superar o essencialismo de 'raça' e sexo, que dificulta o acesso a novas oportunidades nas vidas das mulheres negras.

Em sua investigação a autora supera diversas dific uld a des metodológ ic as, como o fa to de ocupar um cargo de liderança em organização que investig ou e a o mesmo tempo buscar uma imparcialidade e confiança das entrevistadas, a pesar das implic ações políticas do seu cargo e das disputas de interesses existentes nessas organizações. Entretanto, Sudbury conseguiu superaressa situaçã o que lhe dific ultava o a cesso às organizações que visava 
investigar, conciliando em ambos os lugares socia is seus conhecimentose informações de que dispunha, benefic iando a ssim essa sorga nizações. Desse modo, os objetivos de ambas as partes foram sendo alcançados, o que gerava satisfação mútua. Tal solução veio a o encontro do objetivo de que sua experiência como pesquisa dora e seus conhec imentos como a tivista pudessem contribuir para o fortalecimento das mulheres negras e suas organizações. Assim, salienta-se que, apesar dos lugares socia is de ativista e de pesquisadora ocupados concomitantemente pela autora, ela consegue soltar-se de amarras relacionadas a essas posições, tecendo crític as perspicazes e demonstrando alto grau de lucidez ao apontar preconceitos e incoerências nas teorizações e práticas dessas mulheres negras.

o capítulo metodológico, na verdade, consiste em uma crítica à 'sociologia branca', ou seja, a o 'ra ciona lismo c ientífic o social', critic and o as premissa sepistemológic as que funda mentam a ciência sociológica branca que defende 'verdades universais' em prejuízo dos grupos minoritários e de seus saberes locais, padronizando na análise uma perspectiva européia masculina.

Vá ria s questões problemátic a s existentes na realidade das mulheres negras podem ser apontadas, como a violência de mulherescontra outras mulheres, a violência dos homens negros contra as mulheres negras e racismo por parte de algumas mulheres negras, assim como também exclusão de lésbicas das lutas das organizações de mulheres negras.

Toma-se nec essá rio desmistific a r uma visão idealiza da de homogeneidade nas organizações de mulheres negras que mascara diferenças, evidenciando que estas existem, assim como também estão presentes contra dições e formas de opressã o nessas orga niza ções e um a lto grau de complexidade na realidade dessas mulheres. Isso revela a falácia de uma unidade de propósitos e luta entre todas as mulheres, e também entre todos os negros, ignorando as diferenças, sejam de 'raça', gênero e também de classe social, sexualidade, e outras condições de vida, como por exemplo o fato de ser mãe solteira, o que constitui sistemas de opressão integrados.

Nesse sentido, as diversas minorias pertencentes a uma categoria maior, "mulheres negras", muitas vezes não sentem suas necessidades contempladas nas organizações das mulheres negras, as quais, sustentadas em uma idéia de suposta homogeneização, acabam suplantando interesses e velando conflitos, como é o caso das lésbicas, excluídas pororga nizações negras que possuem uma concepção hegemônica patologizante de sexualidade, ocasionando cisões em um pretenso movimento unificado, questões essas que complexificam sobremaneira a compreensão das organizações de mulheres negras na Grã-Bretanha.

Existe também uma idealização que as mulheres negras investigadas fazem delas mesmas, inclusive citando heroínas mitific adas e deusas de diferentes religiões como modelos, 0 que acaba fazendo com que as mulheresignorem suas fraquezas e busquem somente suas forças, procurando ser supermulheres, o que conduz à frustração.

Apesar de diversas ativistas negras se autodenominarem feministas, há um movimento crescente de crítica a esse conceito como característico do pensamento e da ação das mulheres brancas contra o sexismo. E assim as mulheres negras têm preferido o termo "womanismo". Womanismo é definido como uma perspectiva de valorização da mulher em todos os seus âmbitos de ação e relação, não possuindo, no entanto, uma conotação política, como é o caso do feminismo. Na realidade, o feminismo parece designar uma perspectiva de posicionamento da mulher branca, ignorando vivências ma is espec ífic as da rea lida de cotidiana que assolam as mulheres negras, não contempladas pelo conceito de feminismo.

Para uma compreensão mais acurada da opressão sofrida pelas mulheres negras, faz-se nec essá rio a ritic ula ros conceitos de gênero, 'raça' e classe social, constituindo um todo complexo cujas partes se inter-relacionam, o que caracteriza uma situação específic a dasmulheresnegras, que não se encontra nas vivências das mulheres brancas e nem nas dos homens negros. Sendo a ssim, a a rtic ulação entre 'raça' e gênero origina categorias complexas: "racismo de gênero" e "sexismo racializado", relacionados às posições de classe assumidas, tomam-se conceitos que permitem uma compreensão ma is a mpla e crítica da situação vivenciada pelas mulheres negras.

Se por um lado pode-se a firmar que 'raça', como uma realidade que se auto-afirma biologic a mente, sem a mbigüida des, nã o existe, podendo estabelecer diferentes classific ações conforme a cultura de uma determinada região, consistindo antes em um construc to social e históric 0 , o racismo existe e persiste, constituindo realidades e formas de subjetividade. Sendo assim, compreendendo-se ca teg orias id entitá rias como socia is e historicamente construídas, 
escapa-se da obviedade marcadamente biológica da 'raça' e do sexo, concebendo-os como um fenômeno social. Nesse sentido, ao evidenciara identidade como a de mulhernegra, a pagam-se diferenças e ocultam-se as relações de poder que mantêm a ordem socia hegemônica discriminatória, na medida em que não se consideram na análise as diferentes posições a ssumidas pelos sujeitos na sociedade, as quais, além de contemplar 'raça' e gênero, também definem-se a partir da classe social, sexualidade, religião, educação e condições situaciona is diversas. Por esse motivo, toma-se pertinente a substituição do conceito de "política de identidade" por "política de posiciona mento", enfatizando o lugar ocupado pelas mulheres negras no tempo e no espaço, a partir de uma perspectiva ideológica.

Com relação a o conceito de negritude, este é conc ebido a tua Imente por muitas orga nizações socia is como uma "corpolítica", constituindo-se, portanto, em um termo que abrange também quem nã o possui pele escura, como no caso das chinesas, por exemplo, que nesse contexto conceitual denominam suas organizações de negras. Sendo este um conceito utilizado, porta nto, como sinônimo de grupos disc rimina dos e vítimas de racismo, expandindo tal preconc eito para as mais diferentes etnias, pode inclusive abranger os judeus. Tal abertura no uso do conceito de negritude o retira de uma visão essencialista, biologicista, colocando-o como uma categoria histórica e social.

Diante das diversas situa ções de op ressão vivenciadas pelas mulheres negras pesquisa das, elas manifestaram uma compreensão de atuação política em que a luta é travada no cotidia no, não se restring indo à filiação a partidos políticos. Essa concepção do pessoal como político nas organizações de mulheres negras considera as experiências pessoa is como ponto de partida, não desconsiderando, entretanto, a importância da ação coletiva.
As organizações de mulheresnegrasna GrãBretanha têm aderido à proposta de polític a de transformação sugerida por Patricia Hill Collins (1990) de sair da dicotomia entre indivíduo e coletividade, para seguir em um processo de trabalhar primeiramente na transformação e fortalecimento pessoal (a utoconfiança, educação, desenvolvimento econômico/ independência financeira). No entanto, uma ênfase nas mulheres como indivíduos pode conduzir a uma patologização, ignorando a importância da discriminação social sofrida por elas. Após esse primeiro momento, passa-se gradua Imente a questionaro conceito de família saudável; a transformar a comunidade local (o desenvolvimento da consciência em comunidadeslocais); e a formarredesnacionais e intemacionais.

A autora discute bastante a noção de identida de, as classific ações e distinções e suas implicações nas relações socia is/de poder, mas não enriquece/beneficia suas a nálises com a teoria de "poder simbólico" de Bourdieu, autor que ela, em nenhum momento, menciona.

A partir da leitura do livro, pode-se compreendera complexidade dasorganizações de mulheres negras, como a sua relação com os homens negros violentos. Ao mesmo tempo que essas mulheres precisam defender-se desses homens, também precisam preservá-los da estigmatização que eles sofrem, defendendo-os assim dos a ta ques de mulherese homens brancos que visam transformá-los em monstros, o que se constitui em uma das muitas relações contra ditórias em que as mulheres negras se vêem envolvidas. Essa é uma entre tantas situações complexas e contraditórias que as mulheres negras enfrentam em seus movimentos de luta, diante das quais se unem e traçam estratégias diversas em busca da rea lização dos seus sonhos coletivos e individua is.

Sandra Iris Sobrera Abella

Universidade Federal de Santa Catarina 